\title{
TRANSPOSIÇÃO DIDÁTICA DAS TEORIAS DE COESÃO E COERÊNCIA: COMO AJUDAR OS ALUNOS A PERCEBEREM E RESOLVEREM PROBLEMAS NO NÍVEL TEXTUAL
}

\author{
Heloana Cardoso Retondar * \\ Tania Maria Nunes de Lima Camara ${ }^{* *}$
}

\begin{abstract}
Resumo: O objetivo deste artigo é discutir metodologias utilizadas por professores para corrigir problemas de coesão e coerência nos textos dos alunos e apontar possibilidades didáticas. Teoricamente, os estudos sobre textualidade emergiram a partir do sociointeracionismo, entretanto há problemas para se transpor didaticamente seus conteúdos. A discussão é recorte de uma pesquisa qualitativa e indiciária com sete professores. Fundamentado na concepção de escrita como trabalho e autoafirmação, e baseado na avaliação formativa, discute-se: (i) o conteúdo das respostas das entrevistas semiestruturadas; (ii) trechos de redações corrigidas que apresentam problemas de coesão e/ou coerência. Defende-se a hipótese: ao avaliar um texto, não basta sinalizar problemas de coesão/coerência; essa postura metodológica é incoerente com a percepção do texto como o lugar da interação.
\end{abstract}

Palavras-chave: Texto escrito. Avaliação. Coerência. Coesão. Metodologia.

\begin{abstract}
Theoretically, studies on textuality emerged from the Social interactionist theory, however there are problems to didactically transpose its contents. Therefore, this paper, part of a qualitative and circumstantial research with seven teachers, aims to discuss methodologies used by teachers to correct problems regarding cohesion and coherence in students' texts and to point out some didactic possibilities. Based on the conception of writing as work and self-assertion, as well as grounded on formative assessment, it is discussed: (i) the content of the answers to the semi-structured interviews; and (ii) passages from the corrected essays presenting cohesion and/or coherence problems. This paper defends that, when assessing a text, the practice of signaling problems regarding cohesion and coherence is not enough: This methodological approach is inconsistent with the understanding of text as a locus of interaction.
\end{abstract}

Keywords: Written text. Evaluation. Coherence. Cohesion. Methodology.

\section{Introdução}

No imaginário da escola, acredita-se caber ao professor de língua portuguesa a avaliação textual mais "rigorosa". Atribui-se ao professor de português a tarefa de observar cada detalhe do texto, de ajudar o aluno a escrever "com sentido", aperfeiçoando-lhe a escrita. Escrever, por sua vez, constitui uma aprendizagem social, que não se desenvolve sem o ensino e sem a prática. Vale lembrar que o compromisso com o texto cabe aos professores de todas as disciplinas, entretanto, a assertiva, na prática, ainda é uma utopia.

É sobre a tarefa de ensinar a escrever a partir da correção do material produzido pelo aluno que nos dedicamos nos últimos anos. Um assunto preconizado pelos órgãos que orientam o ensino, mas que ainda encontra pouca produção científica e que esbarra numa prática não raro sofrida, pois muitos professores, por serem ainda mal remunerados, precisam assumir diversas turmas, o que acaba transformando a tarefa de corrigir em "produção em série", uma vez que corrigem redações aos montes - em casa, nas horas que deveriam ser de descanso. Como relatado por alguns dos professores investigados, corrigir é "chato", "penoso", "cansativo".

\footnotetext{
* Doutoranda em Letras pela Universidade do Estado do Rio de Janeiro - UERJ. Mestre em Letras pela mesma universidade. Endereço eletrônico: hcretondar@gmail.com

** Doutora em Língua Portuguesa pela Universidade do Estado do Rio de Janeiro. Coordenadora do curso de Mestrado em Língua Portuguesa da mesma universidade. Endereço eletrônico: taniamnlc@gmail.com
} 
Este artigo é um recorte de minha dissertação de mestrado, intitulada Avaliação de textos produzidos nas aulas de Língua Portuguesa: abordagens teóricas, questões didáticometodológicas e suas repercussões e orientada pela Professora Doutora Tania Maria Nunes de Lima Camara. Trata-se de uma pesquisa qualitativa e indiciária, na qual foram investigados sete sujeitos, professores, que atuam no segundo segmento do Ensino Fundamental das redes pública e particular do município do Rio de Janeiro. Os professores cederam produções escritas de algumas turmas e avaliadas por eles para que se pudessem observar as marcas deixadas sobre o texto, bem como participaram individualmente de uma entrevista semiestruturada.

A análise indiciária (GINZBURG, 1989) sugere que se investigue, além das recorrências, o episódico, o singular, dados comumente negligenciados ou descartados em outros paradigmas investigativos. Entre as recorrências, o que se pôde perceber foi a presença da abordagem teórica sociointeracionista nas falas dos professores-informantes. Todos afirmaram não serem os aspectos gramaticais ou ortográficos o foco das avaliações (estes constituíam apenas alguns dos itens a serem avaliados); para os sujeitos investigados, ao avaliar, os aspectos ligados à coesão e à coerência constituíam o foco principal. Na fase de análise do material corrigido, contudo, observou-se, singularmente, que apenas dois dos sete professores interferiam no texto de maneira significativa para que os problemas ligados ao conteúdo destacado como foco principal pudesse ser, de fato, resolvido.

Acreditamos que, assim como no grupo amostral selecionado para a pesquisa, a realidade de ensino da língua ainda se depara com o mesmo quadro, ou seja, professores formados à luz do sociointeracionismo, mas que não fazem transposição didática de alguns de seus conteúdos, sobretudo daqueles que se afastam das orientações que receberam durante o estágio como estudantes. Por isso, separamos para este artigo algumas discussões e sugestões didáticas passíveis de serem aplicadas. De fato, muitas vezes, como professores, na cansativa (porém imprescindível e dialógica) tarefa de avaliar textos escritos por nossos alunos, acabamos por reproduzir a maneira como fomos corrigidos no passado. Tornar a tarefa de avaliar menos intuitiva e mais constitutiva é o que propomos.

Vale ressaltar que não apresentaremos uma proposta metodológica, mas intentamos lançar luz sobre a prática, sugerindo caminhos para serem pensados, repetidos e melhorados. Assim, o objetivo deste artigo é discutir metodologias utilizadas pelos professores investigados e apontar caminhos a respeito de como o professor pode interferir de maneira significativa ao avaliar uma produção escrita que apresenta problemas de coesão e/ou coerência. Assuntos esses que, teoricamente falando, emergiram sob nova roupagem a partir da concepção sociointeracionista de linguagem, mas que, como dito, esbarram numa prática estruturalista de corrigir textos que não contribui para a solução do problema.

Para orientar essa discussão foram selecionados: (i) o conteúdo das respostas a duas perguntas feitas durante as entrevistas semiestruturadas (Como você concebe a escrita dos seus alunos? O que mais incomoda você na produção escrita do seu aluno?); (ii) trechos de redações dos alunos que apresentavam problemas relativos à coesão ou coerência. Os dois corpora ilustram a seguinte hipótese: ao avaliar uma produção escrita do aluno-sujeito, não basta apenas sinalizar problemas de coesão e coerência, já que essa é uma postura metodológica focada no sistema, incoerente com a percepção do texto como o lugar da interação (concepção sociointeracionista).

\section{Avaliar textos escritos em sala de aula: uma prática simbólica, formativa e constituinte}

A atividade de avaliar é uma prática formativa, exige do professor uma base conceitual definida e uma posição didático-metodológica afinada. Do contrário, ecoarão 
reclamações de que os textos dos alunos não fazem sentido, que eles escrevem mal, sem que nada seja feito para interferir nessa realidade. Para Luckesi (2011), a avaliação formativa é constituinte do ato pedagógico e deve avaliar não apenas os alunos, mas também o professor, o processo, as práticas enunciativas, a mediação, a escola e a família. Entretanto, apesar de esse modelo de avaliação ser preconizado pelos Parâmetros Curriculares Nacionais (PCN), o que se observa na prática é a avaliação tradicional, que se opõe à formativa, porque busca apenas medir o conhecimento; o professor recorrentemente marca erros e desconta pontos por eles. Aquela produção verbal em que o aluno empreende esforços para construir sentido se encerra com a nota e não raro o processo também se encerra ali.

Acreditamos que a escrita é trabalho (FIAD E MAYRINK-SABINSON, 1991), autoafirmação, manifestação do desejo; é um desnudar-se diante do outro (BERNARDO, 2000). Além da aferição de um valor à produção textual, que, para o professor, pode ser apenas uma tarefa técnica, estão sendo passadas outras mensagens simbólicas, semióticas e significativas para o aluno (CARDOSO, 2013), que recebe de volta o que pode ser chamado de atitude responsiva (BAKHTIN, 2010) desse mesmo professor sobre o texto produzido.

Por simbólicas se entendem as mensagens transmitidas a partir dos movimentos feitos pelo professor, como, por exemplo, pedir uma reescrita e não a corrigir, representando que aquela não é uma tarefa importante. Por semióticas, são entendidas as marcas deixadas sobre a produção escrita, que funcionam como mensagens para os alunos; um visto, por exemplo, pode ser compreendido como "vi e não li". E, por significativas, são compreendidas as ações simbólicas e semióticas operando sobre o comportamento do aluno como atitude responsiva de efeito retardado (BAKHTIN, 2010). Isso porque toda prática de correção é uma prática dialógica e constituinte.

Para efeito de reflexão, convidamos o leitor a pensar em algo que fora "dito" pelo professor através de uma redação corrigida ao longo de seu lugar social de estudante. Não é preciso muito esforço para lembrar-se de uma nota ruim quando se achava que o texto estava muito bom, sem jamais entender o porquê daquela nota; ou um comentário de um professor que nos fez sentir "o escrito". Se a memória é capaz de trazer à tona esses sentimentos, essa é uma justificativa empírica para se debruçar sobre o estudo do tema.

O processo ensino-aprendizagem da escrita pressupõe o papel social do avaliador, do par mais competente diante do menos competente. Mostra-se inerente a esse ato a necessidade de interferir, de dialogar, de orientar. Marcamos, formamos e constituímos representações dos sujeitos-alunos quando deixamos nossas marcas sobre seus textos.

É importante, pois, reconhecer que, além do material linguístico produzido pelo aluno, ali também estão aspectos sociais, cognitivos, subjetividades, crenças, medos, tentativas de acerto, marcas biográficas que se confundem com a história de um processo pedagógico. Sobre o papel, o sujeito se desnuda e o que nós professores fazemos com essa "exposição"? Além de ajudar o aluno na construção do conhecimento, é tarefa do professor reconhecer que cada aluno, ao escrever, considera a imagem que tem de si: "a imagem da imagem que seu interlocutor tem dele, assim como a imagem que têm do referente, no caso, a língua, [e] buscam reproduzir os traços linguísticos legitimados como "os corretos"" (AZAMBUJA, 2010, p. 289). Por isso, nossas marcas precisam desligar o "piloto automático" e o texto produzido deve funcionar como pesquisa, como processo, como um devir.

\section{Coesão e coerência e avalição textual}

Atualmente, muitos autores se debruçam sobre os fatores de textualidade, sem, contudo, haver um consenso. Ruiz (2001) e Marcuschi (2008) citam Beaugrande e Dressler (1981) como os primeiros a definirem os fatores de textualidade: intencionalidade, 
aceitabilidade, situcionalidade, informatividade, intertextualidade, coesão e coerência. Essa proposta de separação, contudo, é essencialmente didática. Na realidade de uso da língua, diante de um texto, os fatores estão amalgamados nas escolhas linguísticas, resultantes do contexto, das intenções e dos conhecimentos daquele que diz/escreve.

A coesão se refere às estruturas sequenciais e à articulação entre essas estruturas no texto, que se apresentam por meio dos caracteres léxico-gramaticais. Koch (2009) define cinco mecanismos de coesão textual propostos por Halliday \& Hassan: referência; substituição; elipse; conjunção e coesão lexical.

Por sua vez, a coerência também diz respeito às relações estruturais do texto, embora não possa ser vista superficialmente como a coesão. Segundo Koch e Travaglia (2001), é a manutenção da coerência que oportuniza ao texto ser compreendido como um todo significativo. Verificar a coerência textual por meio da simples análise estrutural é, pois, uma tarefa inviável, já que os fatores determinantes de sua existência são elementos linguísticos, conhecimento de mundo, conhecimento compartilhado e inferências. A coerência está relacionada à atividade do leitor sobre as possibilidades interpretativas do texto (MARCUSCHI, 2008).

A intencionalidade está relacionada aos objetivos do autor e à expectativa de que o leitor capte intenções. Aceitabilidade é a contraparte da intencionalidade, pois diz respeito ao cálculo de intenções por meio do receptor. A situcionalidade está relacionada à situação contextual de produção e às marcas dessa situação impressas no texto. A intertextualidade é a relação existente entre dados do texto e dados de outros textos, é a materialização das teorias sobre o enunciado, segundo as quais cada novo texto responde a enunciados anteriores, é a comprovação da alternância dos sujeitos no discurso (BAKHTIN, 2010).

Enquanto Ruiz concorda com esses fatores, citando inúmeros trabalhos de Koch, sua orientadora, e interpretando tais critérios como "fatores que permitem que um texto seja considerado a unidade básica de manifestação da linguagem" (2001, p. 45), Marcuschi (2008) os aceita com ressalvas. Sua crítica reside, primeiro, na separação entre os critérios, considerada "estanque" e "categórica". Em segundo lugar, questiona a redundância de alguns critérios e acredita não ser possível concentrar a visão de texto nem somente na forma, nem somente no código. Em terceiro, considera que a separação pode sugerir a primazia da forma; e, por último, tem para si que tais critérios não podem ser vistos como princípios de um texto bem formado. Como se vê, apesar de as contribuições sociointeracionistas haverem estabelecido nova roupagem para a maneira de compreender o texto, ainda estamos em plena construção do pensamento científico sobre o tema. Esse "estado em construção" também pode ser apontado como um dos responsáveis pela dificuldade em transpor didaticamente tais conteúdos.

O texto "é uma proposta de sentido", admite-se que "ele só se completa com a participação do seu leitor/ ouvinte" (MARCUSCHI, 2008, p. 94); o ato de avaliar é, por isso, de extrema importância, na medida em que é o outro que dá ao texto a noção de "acabamento" (BAKHTIN, 2010). Ensinar os fatores de textualidade considerando a proposta de ensino dos gêneros discursivos, no interior da concepção de escrita como trabalho (FIAD e MAYRINK-SABINSON, 1991), pressupõe admitir os sujeitos como capazes de refletir sistematicamente sobre sua intenção comunicativa e sobre os objetos linguísticos a serem utilizados para atingi-la. É por meio da interação, da avaliação do outro, principalmente do professor, que o estudante se tornará mais competente para a escrita.

\section{Problemas de coesão e coerência nos corpora}


Duas perguntas objetivaram identificar o que os professores buscam durante a sua correção, uma mais indireta e outra mais direta. A primeira delas foi a seguinte: Como você concebe a escrita dos seus alunos? Nas respostas, os professores, em geral, tentaram demonstrar os problemas que percebiam, citaram exemplos e, fazendo isso, davam pistas sobre o que os incomodava, sobre qual aspecto sua atenção estava voltada e mesmo sobre suas representações e expectativas sobre a escrita dos alunos. A outra perguntava, de maneira mais direta: $O$ que mais incomoda você na produção escrita do seu aluno?

Os sete informantes afirmaram incomodar-se mais com os "problemas relativos à textualidade", explicaram que "texto é sentido", que a "coesão" e "coerência" são os elementos que recebem maior peso avaliativo e que os "critérios de textualidade" são o principal objeto de suas correções. Na prática, ou seja, nos textos corrigidos por eles e fornecidos para a pesquisa, as correções oscilam entre a concretização e o distanciamento desse discurso. Problemas de coesão e de coerência são sinalizados como de mesma naturezade outros existentes e nem sempre a indicação do professor favorece a reflexão linguística por parte do aluno. A Fig. 1 apresenta um desses casos:

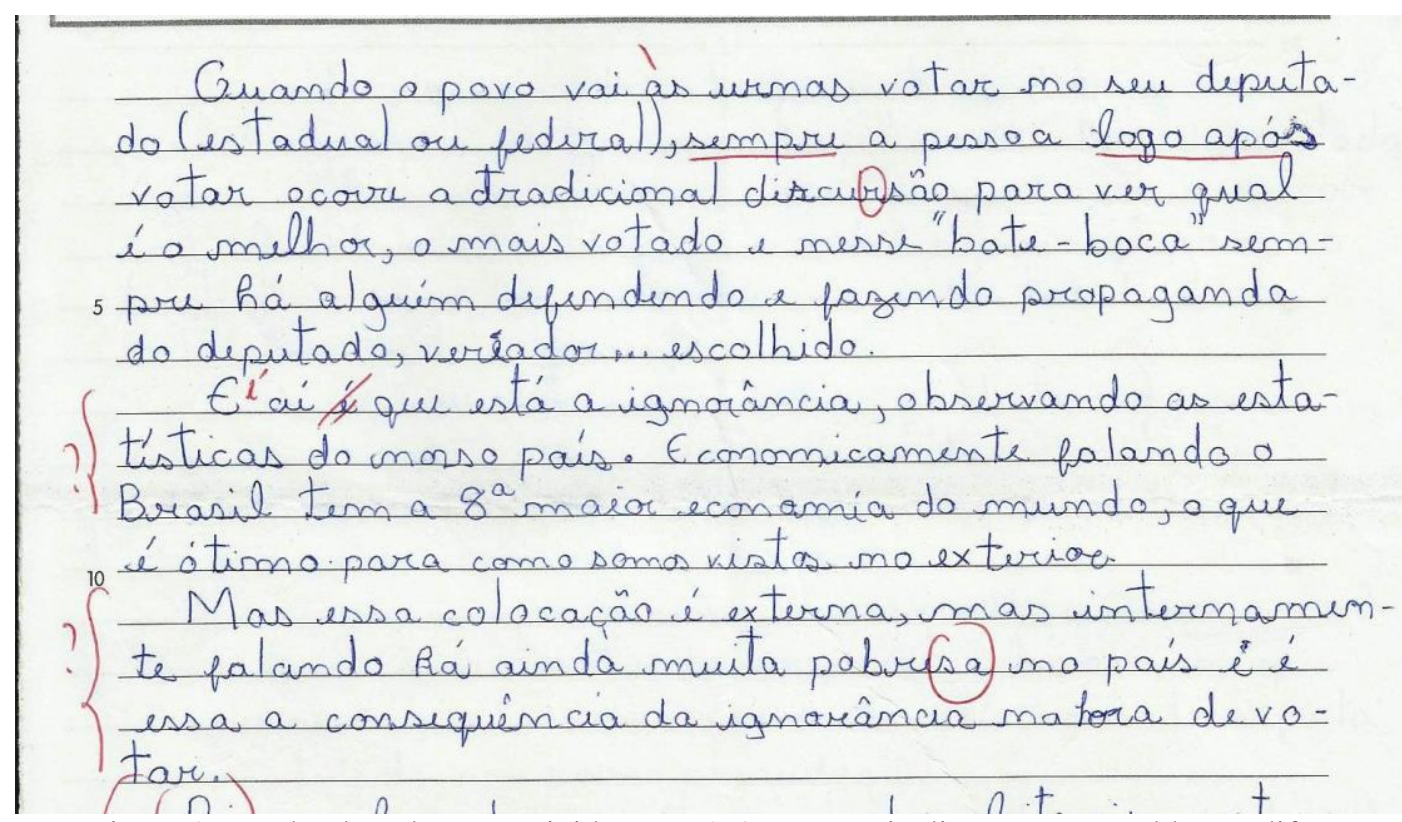

Figura 1: Trecho da redação corrigida por P5. A mesma sinalização para problemas diferentes.

$\mathrm{O}$ que significam as duas interrogações e as chaves nos segundo e terceiro parágrafos? Parece que o segundo parágrafo foi sinalizado porque a frase topicalizada " $E$ ai é que está a ignorância", na qual o "aí" estabelece coesão com o primeiro parágrafo, não progride depois da vírgula na frase "observando estatísticas do nosso país". Trata-se de um problema de estrutura que se solucionaria deslocando o trecho topicalizado para o final do primeiro parágrafo.

A má estruturação do parágrafo gera outro problema: ele apresenta um dado estatístico, que, da maneira como foi escrito, suscita incoerência; em outras palavras, o aluno assegura: "A ignorância está em ter a $8^{\mathrm{a}}$ maior economia do mundo"!?

No terceiro parágrafo, também ocorreu um problema de sequenciação, similar ao erro anterior, mas as consequências foram outras. O aluno começa o parágrafo fechando a ideia do segundo ("Mas essa colocação é externa") e, logo em seguida, apresenta um dado novo, usando o conectivo "mas". Percebe-se que sabe o que quer dizer, mas não consegue estruturar suas ideias para ser bem compreendido. Ele não consegue estabelecer a relação 
lógica de oposição entre os argumentos de prova concreta (posição econômica do país) e o de causa/consequência (voto sem consciência gera pobreza), e acaba escrevendo uma informação confusa: a colocação do Brasil e a pobreza são frutos da ignorância na hora de votar. Quanto à pobreza, não há problemas, entretanto, uma boa colocação econômica não é um bom argumento para defender a tese de que há "ignorância na hora de votar".

Para que percebesse o seu erro, o professor precisaria fazê-lo compreender que há um par concessão/restrição entre os argumentos de causa e de consequência e o de provas concretas que escolheu usar. Além disso, deveria mostrar a necessidade de reorganizar linguisticamente os argumentos, apresentando essa relação lógica na defesa de sua tese.

Observando a recorrência da coordenativa "mas" no parágrafo, pode-se dizer que aluno sabe que se trata de uma oposição, mais do que isso, que se trata de uma discrepância, tanto que usou as informações para argumentar. $\mathrm{O}$ que ele não sabe é como relacionar esses conteúdos e quais os melhores recursos linguísticos (coesivos) para fazê-lo. Dificilmente solucionará o problema com a opção metodológica de correção da professora. Aliás, pode nem conseguir saber qual o problema, porque o ponto de interrogação e as chaves não dão nenhuma pista.

Ruiz (2001) classifica esse modelo de correção como "indicativa" e demonstra, depois de analisar o corpus de sua pesquisa, que, geralmente, o aluno, na reescrita, não modifica o texto diante dessa opção metodológica de correção. Segundo a autora, isso ocorre pelas seguintes razões: a) o aluno não quer efetuar as correções; b) o aluno não sabe o que fazer para resolver o problema; c) o aluno não compreende qual é o problema. Para a pesquisadora, "a indicativa 'pura', sem reforços adicionais de nenhuma outra espécie, não fornece, pois, pistas suficientes de revisão" (2001, p.80). Até mesmo para fazer essa análise, tivemos dificuldades de entender exatamente o que P5 indicou na correção.

Voltando à Fig. 1, como se pode notar, ambos os parágrafos assinalados apresentam problemas de sequenciação na progressão temática e geram diferentes consequências textuais. Enquanto no terceiro parágrafo do texto, a divergência entre o tema (elemento conhecido do leitor) e o rema (o que se diz a respeito do tema) ocorre por problemas no estabelecimento de relações lógicas $(\mathrm{KOCH}, 2009)$, gerando apenas uma dificuldade na leitura, no segundo, o problema de sequenciação prejudica a coerência da informação já que houve a construção de uma sentença incompatível com a realidade (THEREZO, 2012).

Segundo Oliveira (no prelo), um eficiente meio de ensinar a argumentar por escrito é demonstrar a utilização do par 'concessão/restrição', a fim de persuadir o leitor. A partir das frases redigidas pelos alunos e que apresentam problemas como o exposto anteriormente, é possível trabalhar esse par com a turma. O procedimento didático deve ser evidenciado de maneira pontual. O exemplo do texto do aluno de P5 foi organizado a seguir (Quadro 1), sugerindo duas formas estruturais no intuito de ajudar o aluno a solucionar o problema:

\begin{tabular}{|c|c|c|} 
Estrutura 1 & Quadro 1: Estruturas para o par 'concessão/restrição' \\
\hline Concessão & $\begin{array}{c}\text { Adversativa } \\
\text { +restrição em forma de } \\
\text { argumento pró-tese }\end{array}$ & Conclusiva + TESE \\
\hline $\begin{array}{c}\text { O Brasil tem a } 8^{\mathrm{a}} \\
\text { maior economia do mundo, }\end{array}$ & $\begin{array}{c}\text { mas internamente } \\
\text { ainda há muita pobreza }\end{array}$ & $\begin{array}{l}\text { portanto é preciso escolher melhor os } \\
\text { candidatos na hora de votar. }\end{array}$ \\
\hline
\end{tabular}

Estrutura 2

\begin{tabular}{|c|c|ccc|}
\hline \multicolumn{1}{|c|}{ Concessão } & \multicolumn{1}{|c|}{$\begin{array}{c}\text { Adversativa } \\
\text { restrição em forma TESE }\end{array}$} & $\begin{array}{c}\text { Explicativa + argumento } \\
\text { pró-tese. }\end{array}$ \\
\hline $\begin{array}{c}\text { Admite-se que o } \\
\text { Brasil tem a } 8^{\text {a }} \text { maior economia } \\
\text { do mundo, }\end{array}$ & $\begin{array}{l}\text { contudo é preciso } \\
\text { escolher melhor os candidatos na } \\
\text { hora de votar. }\end{array}$ & $\begin{array}{l}\text { pois ainda há muita pobreza } \\
\text { internamente. }\end{array}$ & \\
\hline
\end{tabular}


É importante ainda indicar para o aluno as escolhas estruturais possíveis, suas marcas linguísticas próprias e as diferentes relações de sentido. A seguir, ainda utilizando o problema apontado no texto, são elencadas as diferentes maneiras que Oliveira (no prelo) sugere como possibilidades linguísticas para apresentar o par 'concessão/restrição':

a) Concessão, mas (porém, contudo, no entanto) restrição.

Ex.: O Brasil tem a $8^{\mathrm{a}}$ maior economia do mundo, mas internamente há muita pobreza.

b) É claro que (é evidente que) concessão. O problema é que restrição.

Ex.: É claro que o Brasil tem a $8^{\mathrm{a}}$ maior economia do mundo. O problema é que internamente há muita pobreza

c) Mesmo [+ gerúndio $]$ concessão, restrição.

Ex.: Mesmo o Brasil tendo a $8^{\mathrm{a}}$ maior economia do mundo, internamente há muita pobreza.

d) Embora [+ subjuntivo $]$ concessão, restrição.

Ex.: Embora tenha a $8^{\mathrm{a}}$ economia do mundo, internamente há muita pobreza no Brasil.

e) Apesar de [+ infinitivo $]$ concessão, restrição.

Ex.: Apesar de ter a $8^{\text {a }}$ economia do mundo, internamente há muita pobreza no Brasil.

f) Restrição, embora [+ subjuntivo] concessão. (equivalente invertido de "d")

Ex.: Internamente há muita pobreza no Brasil, embora tenha a $8^{\mathrm{a}}$ economia do mundo.

g) Restrição, apesar de [+ infinitivo] concessão. (equivalente invertido de "e")

Ex.: Internamente há muita pobreza no Brasil, apesar de ter a $8^{\mathrm{a}}$ economia do mundo. (OLIVEIRA, no prelo)

Como se vê, é possível promover reflexão linguística para solucionar problemas relacionados à coesão e à coerência. A interferência significativa afasta o ato de corrigir como sendo uma simples sinalização, exibindo-o, ao contrário, de maneira formativa; o problema do texto passa a ser material para planejar as próximas aulas, que devem, inclusive, ser discutidas com toda a turma. Exemplos retirados de textos dos alunos são sempre muito úteis.

Conjugar reflexão linguística e solução de problemas de superestrutura textual exige, portanto, muito mais que um ponto de interrogação ao lado do parágrafo. Abordagens metodológicas significativas como a descrita acima podem ser adaptadas e aplicadas na ocorrência dos seguintes problemas:

A. repetição (sequência textual desajeitada, presença de rupturas);

B. falta de progressão (aspecto semântico comprometido, falta de balanceamento entre o dado e o novo);

C. contradição (falta de harmonia entre os elementos semânticos);

D. ausência ou comprometimento de relações (relação entre os fatos, os dados).

Cada um dos itens anteriores diz respeito a elementos supraestruturais (coerência), orientando os elementos estruturais (coesão). A concepção estruturalista de linguagem não abrange elementos textuais, principalmente porque sua maior unidade de análise é o período. Por isso, sublinhar estruturas, inserir um ponto de interrogação, uma chave, um colchete ou mesmo a palavra "confuso", além de sinalizar uma concepção estruturalista, não dá pistas de 
como solucionar o problema. Nesse caso, a abordagem teórica torna-se incompatível para interferir no campo da didática.

Apesar de opções metodológicas como a de P5 terem sido recorrentes no corpus analisado de outros informantes, esse resultado não foi regra. Encontram-se também trabalhos que conjugaram o discurso sociointeracionista compráticas dialógicas próprias dessa teoria, indiciando uma mudança no papel do professor de português no desenvolvimento da escrita do aluno. Na Fig. 2 é possível observar como a intervenção do professor pode conduzir o aluno a uma reflexão sobre seu próprio texto:

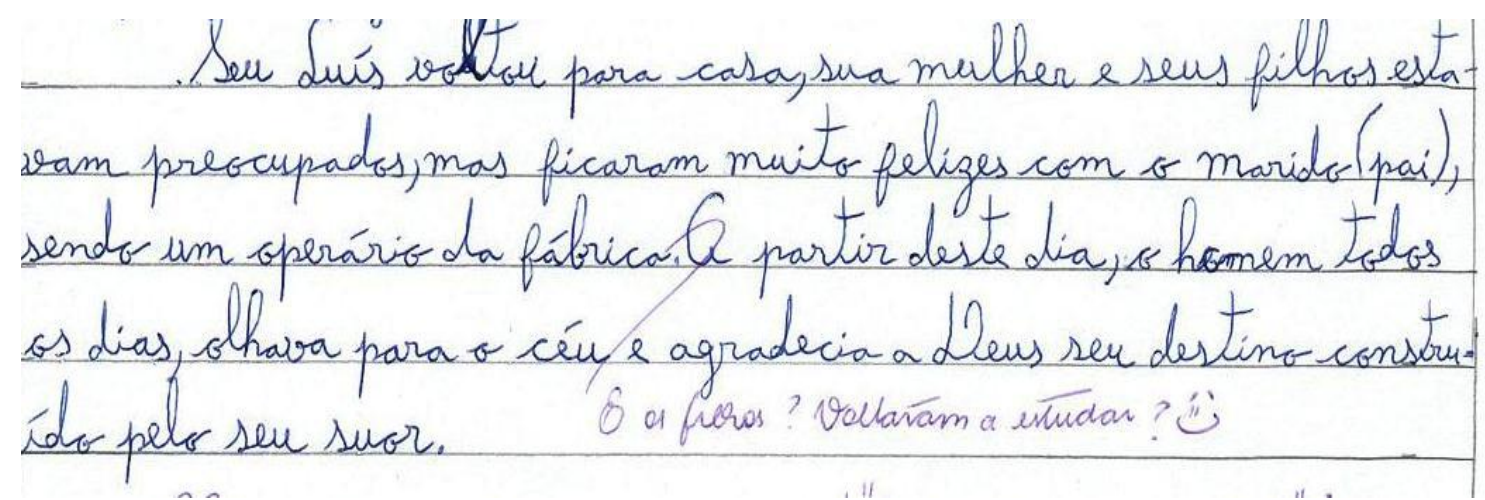

Figura 2: Trecho da redação corrigida por P4 em que há uma interferência significativa para a orientação da reescrita.

Aqui, o professor aponta exatamente a sua dúvida diante do texto. Houve uma incoerência interna, na estrutura da narrativa. É preciso um desfecho para os fatos narrados, e os filhos, que aparecem como personagem no início, se apagam ao longo do texto; portanto, quando falta um dos constituintes da estrutura narrativa, o problema deve ser sinalizado. Se a pergunta fosse mais aberta, como "O que aconteceu com os filhos?", poderia gerar novos problemas, tais como falar algo para responder à pergunta do professor, mas não necessariamente solucionar o problema do desfecho da narrativa, pois o aluno poderia simplesmente responder ao bilhete, sem considerar o texto.

Penteado e Mesko (2006) chamam de réplica quando um aluno, na reescrita, estabelece o diálogo com o bilhete, mas não incorpora a resposta no texto, já que, no caso, não é possível perceber estratégias discursivas que garantam o fio temático da primeira versão. Embora o professor investigado não tenha falado nada sobre a melhor maneira de responder a um texto, sua atitude leitora, mais do que avaliadora, direciona o pensamento do aluno para que, no momento da reescrita, resolva o problema do desfecho e não somente responda ao bilhete. A partir do exemplo, afirma-se que os papéis de leitor e avaliador não são dicotômicos, mas complementares.

P4 confessa que interferências que dialogam com o texto em tipologia narrativa são mais fáceis. Quando se ensina a argumentar, aparecem problemas pontuais que dizem respeito à própria natureza do argumentar, como, por exemplo, a falta de argumentos. Isso pode deixar o texto mais expositivo e menos argumentativo. Afirma que precisa descobrir estratégias para lidar com os textos argumentativos. Conforme sua concepção de correção, ele não deve interferir demais no texto do aluno. Cita, como exemplo, uma proposta de redação que pedia um posicionamento sobre os meninos de rua. Uma das redações falava que a situação era triste, que os meninos precisavam de ajuda, que algo devia ser feito para mudar aquela situação etc, mas não expunha o motivo do problema. P4 diz que tentou perguntar no bilhete: por que esses meninos estão na rua? E, segundo seu depoimento, o aluno respondeu com um sintagma preposicionado "por causa do governo", e continuou não argumentando.

Em virtude desse dado, cabe abrir um espaço para tentar responder à indagação do professor, que, como dado singular, merece tratamento científico. Uma das possíveis causas 
de o aluno de P4 não apresentar argumentos é a proposta de redação. Oliveira (no prelo) distingue a dissertação expositiva da argumentativa da seguinte maneira: enquanto a primeira é usada para expor, para discorrer sobre um tema, cuja atitude do escritor é mais imparcial e informativa, a segunda apresenta argumentos em favor de uma opinião (tese) defendida pelo autor. Para a última, portanto, é preciso que o autor assuma uma atitude polêmica que tente persuadir o leitor acerca do seu ponto de vista. $\mathrm{O}$ autor lembra que polêmica é derivada de polemos, que significa guerra, sendo preciso travar verdadeira batalha para defender a ideia do argumentador.

Citando Charadeau (2008), Oliveira afirma que, para que tal procedimento ocorra, é necessário que, na proposta de redação, haja um requisito de questionabilidade, ou seja, a proposta deve suscitar questionamentos, pois só há argumentação quando se questiona o dito. O ensino da argumentação pressupõe, portanto, que o professor tenha e transmita informações referentes à estruturação do texto argumentativo. Além disso, a proposta ideal deve conter os seguintes requisitos: (i) ter razoável grau de especificidade; (ii) ser atual; (iii) provocar debates fora da sala de aula; (iv) não requerer conhecimentos especializados; e (v) ser apresentada de maneira aberta, de tal modo que o aluno possa tomar uma posição (OLIVEIRA, no prelo).

Comparando a estratégia de correção de P4 à seguinte, de P2 (Fig. 3), diante de um problema de coerência, é possível perceber qual das duas tem maiores chances de levar o aluno à reflexão sobre a informatividade do seu texto:

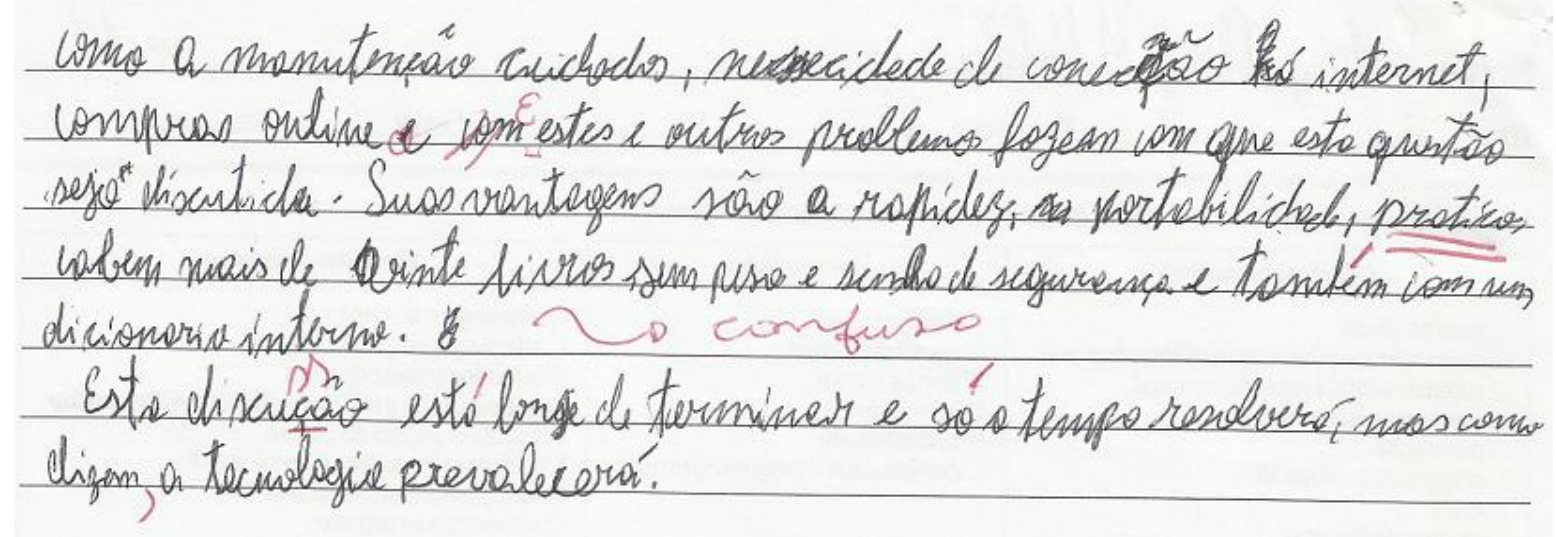

Figura 3: Trecho da redação corrigida por P2 em que não é possível saber qual é o problema.

O que o professor aponta como confuso é a frase "Suas vantagens são a rapidez, a portabilidade, práticos cabem mais de vinte livros sem peso e sendo de segurança e também com dicionário interno." O texto do aluno, que traz como título "Manual ou digital", tenta uma argumentação ponderada para apresentar o que é melhor, o livro digital ou impresso. Segundo Ruiz (2001), indicar o trecho problemático coma palavra "confuso" não ajuda a solucionar o problema.

Calkins, Hartman e White (2008) apontam caminhos para identificar a compreensão que o aluno tem das orientações do professor, e também a compreensão do professor sobre aquilo que o aluno diz e faz. Utilizando a teoria das autoras sobre a arquitetura da interação, é possível perceber que o que ocorre no excerto não é propriamente uma interação, mas apenas uma apreciação valorativa que indica vagamente o erro, sem apontar um caminho para a solução.

No caso, seria mais aconselhável perguntar qual o referente de "suas vantagens", já que o problema é justamente a distância entre pronome e seu referente. Talvez seja isso que o professor chama de "confuso". Por outro lado, a escolha das palavras também deixou o texto truncado: "sem peso e sendo de segurança e também com dicionário interno". Facilmente se 
resolveria o problema se o professor sugerisse que o aluno fizesse o paralelismo sintático, ou seja, usasse complementos de mesma natureza, de mesma classe gramatical, tais como "leve, seguro e prático". Levando a frase para a turma, pode, de maneira indutiva, mostrar o estranhamento, o problema e a maneira de resolver.

Os problemas não ocorrem apenas nas correções indicativas. Seguem, nas Fig. 4 e 5 , outros dois exemplos de como a correção textual-interativa, nomenclatura criada por Ruiz (2001) para o método de correção em que o professor deixa bilhetes para o aluno. Embora a autora apresente essa estratégia como eficaz, como de fato se observa no corpus de sua pesquisa e mais especificamente na Fig. 2 deste artigo, em alguns casos o bilhete pode se apresentar genérico e confuso. A simples comunicação verbal dos problemas não garante a aprendizagem, sobretudo quando se refere ao nível textual: coerência, baixa informatividade, falta de sequenciação, tese mal formulada etc.

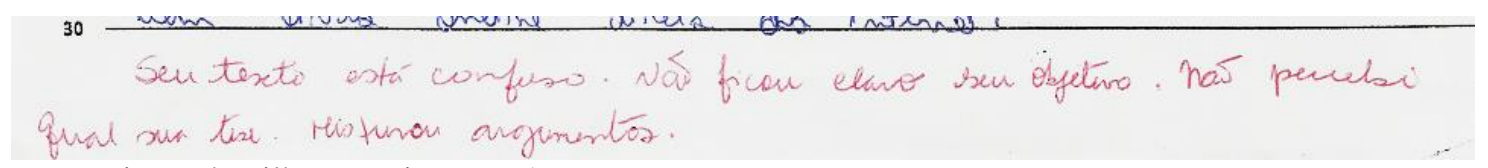

Figura 4: Bilhete escrito por P1 com uma correção vaga.

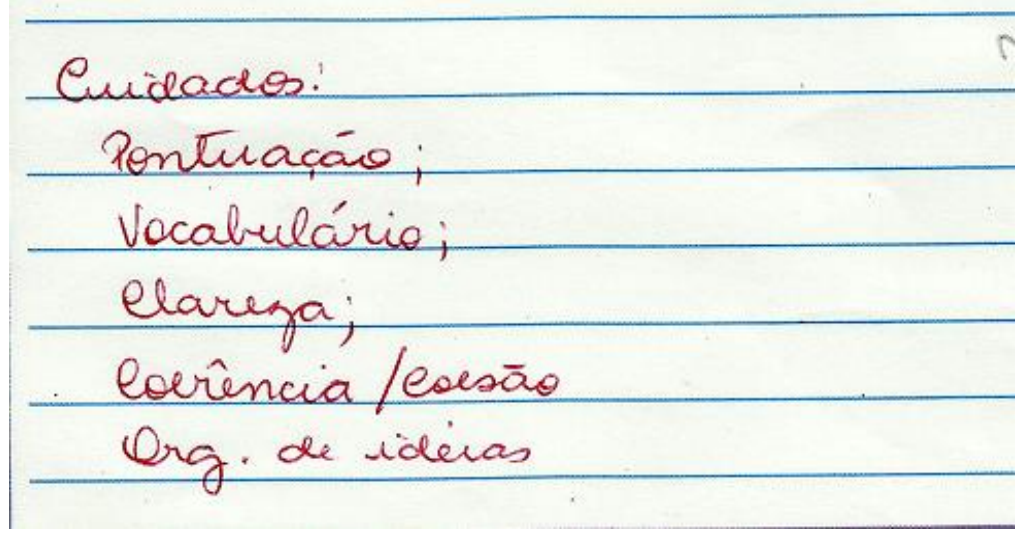

Figura 5: Bilhete de P2 deixado para o aluno ao final do texto. Aqui P2 lista todos os problemas encontrados.

A Fig. 4 ilustra como não basta escrever bilhetes. Se o aluno ainda não sabe o que é a defesa de uma tese, não será capaz de identificar o problema - e este aluno provavelmente não domina o referido conteúdo, já que o próprio professor se refere à falta de clareza dos seus objetivos e à mistura de argumentos. Já o segundo bilhete, Fig. 5, exemplifica como o professor, no afã de deixar o texto impecável, pode abordar problemas de naturezas diferentes, confundindo o aluno, que não saberá identificar onde está cada um daqueles erros listados. No exemplo, P2 dá aos bilhetes menos utilidade do que poderia.

\section{Considerações finais}

A partir dos exemplos apresentados, pode-se afirmar que o material linguístico produzido pelos alunos tem sido menos aproveitado do que deveria. Fica claro que a transposição didática ainda é um problema quando o assunto é avaliar e ensinar aspectos da textualidade.

Ao avaliar uma produção escrita do aluno-sujeito, não basta apenas sinalizar problemas de coesão e coerência, já que, além de essa postura ser incompatível com a 
concepção sociointeracionista de linguagem, ela não oferece caminhos para que se resolvam os problemas. Por outro lado, será preciso conjugar atividades sistemáticas de organização textual, velhas conhecidas da concepção estruturalista, sem, contudo, ser a atividade um fim em si mesma. Seu objetivo é, depois da reflexão linguística e dos exercícios estruturais, voltar ao texto, lançando mão do conhecimento refletido para organizar estruturas de maneira coesa.

Se a tarefa de corrigir for encarada a partir da proposta formativa de avaliar, aquele material escrito deve ser compreendido como o trabalho do aluno em processo, como um ato de se constituir como sujeito que escreve, como uma rica fonte para o planejamento das atividades nas aulas seguintes. É também um balanço de como o conteúdo ministrado é compreendido.

Esperamos que os caminhos apontados sobre possibilidades de interferência para solucionar problemas coesão e/ou coerência possam ser testados, discutidos e aperfeiçoados. E que as perguntas feitas aos professores investigados sirvam de norte para nossas próximas aulas: Como você concebe a escrita dos seus alunos? O que mais incomoda você na produção escrita do seu aluno?, às quais se acrescenta uma terceira: $O$ que estamos fazendo para melhorar aquela escrita do aluno descrita nas respostas anteriores?

\section{Referências}

AZAMBUJA, E. B. Refletindo sobre a produção da "hipercorreção" em textos de alunos de pós-graduação. Cadernos do CNLF [RJ], v. 14, n. 4, t. 4, p. 287-295, ago. 2010. Disponível em:<www.filologia.org.br/xiv_cnlf/tomo_4/completo_tomo_4.pdf>. Acesso em: jan. 2012.

BAKHTIN, M. Os gêneros do discurso. In: . Estética da Criação Verbal. 5 ed. São Paulo: Martins Fontes, 2010. p. 261-306.

BERNARDO, G. Redação Inquieta. 5 ed. Belo Horizonte: Formato Editorial, 2000.

BRASIL. Ministério da Educação e Cultura. Parâmetros Curriculares Nacionais: terceiro e quarto ciclos do ensino fundamental: língua portuguesa/ Secretaria de Educação Fundamental. Brasília, DF: MEC/SEF. Disponível em: <http://portal.mec.gov.br/seb/arquivos/pdf/portugues.pdf> 1998. Acesso em: jan. 2012.

CALKINS, L; HARTMAN, A.; WHITE, Z. Crianças produtoras de texto: a arte de interagir na sala de aula. Tradução por Gisele Klein. Porto Alegre: Artmed, 2008.

CARDOSO, H. Avaliação de textos produzidos nas aulas de Língua Portuguesa: abordagens teóricas, questões didático-metodológicas e suas repercussões. Rio de Janeiro, 2013. 153f. Dissertação (Mestrado em Letras) - Universidade do Estado do Rio de Janeiro.

FIAD, R.S.; MAYRINK-SABINSON, M.L.T. A escrita como trabalho. In: MARTINS, M. H. (Org.). Questões da Linguagem. São Paulo: Contexto, 1991. p. 54-63.

GINZBURG, C. Sinais: raízes de um paradigma indiciário. In: Mitos, emblemas, sinais: morfologia e história. Tradução por Frederico Carotti. São Paulo: Companhia das Letras, 1989 [1939], p. 143-180.

KOCH, I.V. O texto e a construção dos sentidos. São Paulo: Contexto, 1997. 

2009.

; ELIAS, V. M. Ler e escrever: estratégias de produção textual. São Paulo: Contexto, ; TRAVAGLIA, L. C. A coerência textual. São Paulo: Contexto, 2001.

LUCKESI, C. C. A avaliação da aprendizagem: componente do ato pedagógico. São Paulo: Cortez, 2011.

MARCUSCHI, L. A. Produção textual, análise de gêneros e compreensão. 2. ed. São Paulo: Parábola, 2008.

OLIVEIRA, H. F. de. Como ensinar a argumentar por escrito. In: MARTINS, C. F.; CORREA, A. M. da S. (Orgs.). No prelo.

PENTEADO, A. E. de A.; MESKO, W. S. Como se responde a um bilhete? Movimentos a partir desse instrumento de intervenção nas produções textuais em processo de reescrita. In: SIGNORINI, I. (Org.). Gêneros catalisadores: letramento e formação do professor. São Paulo: Parábola Editorial, 2006. p. 71-91.

RUIZ, E. Como se corrige redação na escola. Campinas, SP: Mercado da Letras, 2001.

SOARES, D. A. Produção e revisão textual: um guia para professores de português e de Línguas estrangeiras. Petrópolis, RJ: Vozes, 2009.

THEREZO, G. P. Como corrigirredação. 7. ed. Campinas, SP: Editora Alínea, 2012.

Recebido em: junho de 2015.

Aprovado em: julho 2015. 